\title{
Rebutting Philosophical Scepticism: An Exploration of Wittgenstein's Approach in his on Certainty
}

\section{Ahinpunya Mitra*}

The best evidence in favour of a claim to knowledge warranties not the possibility of our not being wrong, so says the sceptic. Whatever grounds a putative knower has for some claim, always there exists a gap between the grounds and the claim. Antisceptical stands take the form of attempts either to bridge or close the gap. The Cartesian approach for bridging up the gap consists in specifying a guarantee for the subjective ground of beliefs that would secure them from sceptical attacks and elevate them to the status of knowledge. The guarantee is to be sought in the goodness of a deity, which by virtue of its sheer goodness will ensure our not being led into deception in matters of evidences for knowledgeclaims, provided our epistemic endowments are used responsibly. Some not satisfied with the Cartesian tradition sought the guarantee elsewhere -in some basic self-justifying and self-evident beliefs providing foundation to our system of beliefs, which conjoined with the evidences for our claims to knowledge make such claims immune to sceptical attacks.

In the Critique of Pure Reason, Immanuel Kant offered a foundationalist solution to sceptical challenge. According to Kant, we receive sensory data in space-time form. Upon the incoming spatio-temporal sensory data our minds impose a framework of concepts or categories, which transforms the data into experience properly so called. Experience is the result of applying the concepts to the sensory data. We justify our claims to knowledge as against the sceptic by pointing out to these facts about the way experience

Associate Professor of Philosophy, Triveni Devi Bhalotia College, Raniganj, Dist. Burdwan: ahinpunya@gmail.com 
is constituted. Kant said that for his own philosophical ideas he was indebted to Hume. Hume held that philosophical reason is impotent to refute scepticism, but this matters little, for human nature is so constituted that certain beliefs, such as the beliefs in the principle of induction, the existence of the external world, the causal relation obtaining between events in the world, are ineradicable. This view of Hume led Kant to build up his view that the concepts challenged by the sceptic are constitutive features of our capacity to have any experience at all.

Wittgenstein in On Certainty offers a response to scepticism somewhat in the tradition of Hume and Kant, namely, that there are some things we simply have to accept in order to get on with our ordinary ways of thinking and speaking. Such propositions as that there is an external world, or that the world came into existence a long time ago, are simply not open to doubt. It is not an option for us to question them, neither can we say that we know them, for these propositions constitute the framework of discourse within which more particular claims of knowledge and expressions of doubt make sense. In the following pages we will develop Wittgenstein's way of disposing of philosophical scepticism after his On Certainty.

In approaching scepticism, G. E. Moore's response to scepticism becomes Wittgenstein's target too. In response to the Cartesian sceptic's question whether we know that there are any physical objects, Moore in his article 'Proof of an external world' claims to know that he has two hands while holding up his hand in good light and making a pointing gesture towards each of them in turn. It follows that at least two physical objects are known to exist. The fact that he knows these physical objects to exist adequately establishes that the external world comprised of such objects exists. In a later article, A Defence of Common Sense, Moore enumerates a number of propositions which he knows for certain: "I have a body", "The earth existed for a long time before my birth," "I have never been far from earth's surface" etc. Wittgenstein considers Moore's attack on the sceptic to be misplaced. Wittgenstein contends that when a person correctly uses "I know," he must have compelling grounds for this claim and be able to indicate to another what they are. Wittgenstein further contends that when "I know" is 
used correctly, those grounds cannot be less sure than the contention they are used to support. But the problem with propositions which Moore says he knows is that nothing is more certain than these propositions in normal circumstances. The proposition "I have two hands" itself is as certain as any possible evidence to which Moore might appeal. That one has two hands is no less certain before having looked at them than afterwards. Should a person be asked whether he has two hands, he would not normally make sure by looking, since it is not plausible to think that he is more certain of his sight than he is of the existence of his hands. He could have tested his eyes by looking to find out whether he saw his hands. Therefore, in case of a claim to knowledge that one has two hands, no justification of a genuine sort is possible; there is no more rudimentary datum to which Moore can point in support (Martin, 1984, p. 594). Substantiation comes to an end. Since the grounds Moore can give in favour of his assertion that he has two hands are no surer than his assertion, he cannot claim to know the things he asserts.

That Moore cannot claim to know the things he asserts does not mean that his propositions are subject to doubt. Any claim to doubt a proposition also requires sufficient grounds to support that claim. These grounds must be more certain than the proposition doubted, since otherwise one would have a better epistemic basis for rejecting the ground for doubt than for rejecting the proposition which is the target of the doubt. Consider entry 125 of On Certainty:

If a blind man were to ask me "Have you got two hands?" I should not make sure by looking. If I were to have any doubt of it, then I don't know why I should trust my eyes. For why shouldn't I test my eyes by looking to find out whether I see my two hands? What is to be tested by what?

Wittgenstein's argument here is that since nothing is more certain in normal circumstances than the proposition that one has two hands, any doubt in this proposition is necessarily groundless, as any such ground (e.g., that one cannot see one's hands) will be at least as open to doubt as the target proposition. So, any ground for doubt in Moore type propositions would be itself more dubitable than the target proposition itself. Therefore, Moore type 
propositions, those we are most certain of, are logically immune to rational doubt. Hence not only is the Moorean claim to know such propositions improper, the sceptic's claim to doubt such propositions cannot also be properly made.

Propositions which Moore claims he knows are such that we are perfectly certain about them even in the absence of grounds adduced in their favor. As Wittgenstein says, the difficulty is to realize the groundlessness of our believing. The type of certainty that Wittgenstein is after is objective certainty. The certainty is objective as in not based on grounds at all. For once grounds are adduced, we are in the realm of knowledge and justification. This is a primitive and groundless sureness which constitute the fundamental principles of human enquiry. Our knowing something is not our ultimate way of being sure; it does not constitute our fundamental assurance about our world and ourselves. Underlying knowing is a more fundamental breed, a bedrock, a non-epistemic certainty. Knowledge is an epistemic concept, belonging to the language game. The certainties in Moore's repertoire are non-epistemic and stand in a presuppositional, supportive relationship to the language game. Certainties ground the language game and are conditions of its possibility. Knowledge in the end is based upon acknowledgement of a number of propositions which are fused into the foundations of our language games. What makes Moore type propositions certain is the fact that they perform a framework role in normal circumstances. Like rules of our language, these fundamental propositions are deeply embedded in all our speech and thought about the world. They constitute the riverbed or frame work of our entire manner of making empirical judgments about what is true and false. Fundamental propositions are neither true nor false in the sense that these terms apply to ordinary propositions for which one submits evidence. Wittgenstein labels these propositions 'hinge propositions'. These propositions form the hinges around which our inquiries turn. The suggestion, then, is that these propositions are not aspects within the practice of inquiring, but rather in some way constitute it. They are not the result of but the underlying condition for the procedures we follow in our investigations. All our thinking and acting in the world is hinged on a framework of basic certainties that are not grounded on reason. The kinds of 38 
evidences which are acceptable, the possible doubts and questions to which one is entitled, etc., these depend on the fact that some propositions are exempt from doubt, like hinges on which our other proceedings turn. But they themselves are so securely anchored in our method of doubt and enquiry that we cannot touch them. They are indubitable. Thus, if Moore's truths cannot be known, neither can they be placed in question.

In On Certainty, Wittgenstein distinguishes between two kinds of doubt, ordinary doubt and philosophical doubt. Ordinary doubting, like knowing, belongs to the language game. Doubt that belongs to the language game in principle has a terminal point, can be allayed by the adducing of evidence. Indian voters are by and large sceptical of the assurances given by the politicians before election. Voters do not put into doubt the physical existence of the politicians or their origin from the Homo Sapiens genus. Taking lessons from the past, they become sceptical about the realization of the present promises. This kind of doubt is acceptable to Wittgenstein; it belongs to language game and can be resolved. On the other hand, from the fact that humans often err with respect to claims they advance, the philosophical sceptic goes on to argue that since in this case or in that case (in any arbitrarily selected case) one might be mistaken, it is possible to be mistaken in every case. Without making any difference between cases - whether it is the existence of the external world or of other minds - philosophical scepticism imposes a philosophical picture on a diversity of features, absorbing their variety into the model that since one might be mistaken in any given case it follows that one might be mistaken in every case. Philosophical doubt, thus, in principle which goes on endlessly. Both Moore and his sceptical opponent have conflated the notion of doubt with 'philosophical doubt.'

What we call language game consists of linguistic practices giving rise to instructional rules that define certain concepts. Among these would be the concept of doubt. Doubting, like knowledge, is a part of conceptual scheme whose other members include guessing, hypothesizing, thinking, believing. They together form a web of intertwined and related notions that play roles in everyday human intercourse and interaction. Doubting is a social practice, a game. 
Just like a game (for example, football) cannot be played by simply looking inward, but through a certain kind of immersion in a human community like engagement in a set of complex activities that involve other persons and following a set of rules that are formative of the game, doubting is also part of a set of practices that are constitutive of human life.

Let us analyse what Wittgenstein means by the 'game of doubting.' Suppose my friend tells me that Bidesh Bose scored the goal for India against Poland in the 1984 Nehru Gold Cup Football tournament held at Eden Gardens. My recollection is that it was Bisawjit Bhattacharya, which gives me a reason to doubt the claim of my friend and to express my wavering. I have now just begun to play the game of doubting. The game is continued through my effort to find out the right answer, such as checking old news papers, going to libraries and checking clippings and encyclopaedias. This complex process is game because it involves a set of practices, the analogues of rules, such as record keeping, the adducing of evidence, and also involves others, institutions like libraries and a communal background that rests upon uniformity of judgement and agreement. The game ends with finding the right answer in these materials. When the right answer is now shown to my friend, it would be normal for him to accept my opinion. But, if he refuses to accept my report, the game is resumed, and he will be the player now, getting himself involved in a set of activities similar to what I did - going to libraries, checking records, and so on. If his consulting the various records testifies to the truth of my claim, the game is supposed to be over now.

If, however, my friend goes on insisting that it was Bidesh Bose who scored the goal against Poland, arguing that the records are not trustworthy being based on a mistaken source, he will be no longer playing a rational game following established community rules. Wittgenstein says in entry 625 , "But these rules ...only make sense if they come to an end somewhere. A doubt without an end is not even a doubt." Therefore, in the case of my friend, serious doubting has come to an end. My friend is now outside the language game. This is exactly the position of the sceptic who insists that it is reasonable to doubt the reliability of all puttive 
data, including those based upon vision. This sort of obsessive doubt is what Wittgenstein calls "philosophical doubt."

In On Certainty, Wittgenstein is against this extreme kind of scepticism which is by nature obsessive and non-terminating. In entry 315 he says, "It would be as if someone were looking for some object in a room; he opens a drawer and doesn't see it there; then he closes it again, waits and opens it once more to see if perhaps it isn't there now, and keeps on like that. He has not learned to look for things..." The person who opens and closes the drawer again and again has not learned the game of searching. Such an obsessive process, just like the process of checking the date by looking at hundred copies of the same newspaper, lacks a procedure for closure, continues endlessly, and is therefore senseless. The game of searching should be learnt through early training, through living in a family as part of a community in which people search for lost objects. Such training makes one learn that it is senseless to go on opening and closing the drawer obsessively, since nothing can be gained after the first few tries. The person described here is demented. Since his behaviour is not in conformity with mankind, his doubting cannot be entertained. All of us grow up in a community and our behaviour is judged to be sensible or insane according to whether it conforms or not with the rules of such an assemblage. The obsessive sceptic is not behaving sensibly because his behaviour does not conform to the procedures of the community. A doubt is perfectly acceptable if it conforms to community practice. That would have been the case if the man's opening and closing the drawer would come to an end somewhere. Opening and closing the drawer endlessly is going beyond any recognizable community practice (practice of the act of doubting), and hence the man's suppositious worries are not doubts at all.

The sceptical idea that we might always be mistaken is like the idea of miscalculating in all our calculations. In order to say sensibly that we have committed a mistake in calculation, we need to contrast the case with one in which no mistake has been made. With this sort of contrast in hand, the notion that we have miscalculated in this or that case makes sense. If we press our doubts and ask whether it is possible that we have miscalculated in all of our calculations, it would not be a sensible position. In the 
same way, the hypothesis that all things around us do not exist, which entails that we are wholly wrong about every statement we make about physical objects, is not sensible. In doubting all of our calculations and, by analogy, in doubting every statement about physical objects, one is not playing the right game, namely, the "doubting game". One is no longer playing according to the rules of the language game that define the concept of doubting. According to the logic of the language game, the sensible employment of doubt entails that in principle all doubts are resolvable; they cannot sensibly be expressed ad infinitum. As Wittgenstein writes in entry 115, "The game of doubting itself presupposes certainty." He also puts it: "Doubting and nondoubting behavior. There is the first only if there is the second" (OC, 354). In actual practice we do not doubt everything: "The reasonable man does not have certain doubts" (OC, 220). This is how language game is actually played. A language game is possible if one trusts something (OC, 509). In so trusting, one has no thought about verification. Our language with all its games rests upon our certainty about some fundamental propositions. Knowledge, guessing, hypothesizing, thinking, believing, and doubting - these are epistemic concepts belonging to the language game. They together form a conceptual scheme. Moorian certainty does not belong to this system; it stands outside of it. Certainty grounds the language game; it is a condition that makes the language game, that is, this set of activities, possible. If one's ordinary actions were always preceded by or accompanied by doubt, one would be paralyzed - one would stand before the abyss, and ordinary behavior would be impossible. If we doubted everything, even the meanings of the words we use in normal circumstances, thus dragging out the language-game by unremitting doubt, we would soon do away with the language game itself, we could not even talk. Accordingly, we will loose our ability to understand the doubt itself.

The sceptical move from any case to every case would be equivalent to the claim that a game has always been played wrong. In entry 496, Wittgenstein says that it has no meaning to say that a game has always been played wrong. Consider, for example, the game of chess. The game has been played innumerable times for centuries. Suppose that a scholar somehow detects that the first 42 
book describing the game of chess written by the inventor of the game contained a misprint regarding one of the rules that affected the meaning of the rule, and that the mistake has continued in all subsequent works on the subject. Since one of the real rules has never been followed, the scholar concludes that the game of chess has always been played incorrectly. The players playing the game of chess would reject the contention as irrelevant. For centuries they have followed a practice, and that practice, even it involves the following of a wrong rule, has become a history. The historical practice of the game of chess defines what the game is, and one who follows that practice is playing correctly. Accordingly, the scholar's contention that the game of chess has always been played incorrectly is unacceptable. The sceptic, in putting to question the historical practices that define chess playing, is not asking a sensible question at all. Similarly, raising questions about the traditional procedures that define calculating, and about our communal linguistic rules that define what it is to refer to such things as tables and chairs, is to indulge in nonsense.

At one time, there was some doubt whether a planet existed in a certain portion of space-time. Later observations proved that it existed, and this planet was later named "Saturn." But the situation with respect to the existence of Moore's hand is palpably different from the situation with respect to the existence of Saturn. Since Moore was born, never it was doubted by anyone, even when he hadn't offered his proof, whether his hand existed. The possibility of committing mistake gets more and more improbable as we approximate from the case of the planet to that of our hand. As Wittgenstein says, "Doubt gradually loses its sense. The languagegame just is like that" (OC 56). At some point in the transition from the planet case to that of our hand, the mistake ceases to be conceivable. This is the case with a vast number of propositions which count certain for us, including Moore's truisms. With respect to earth's existence etc., Wittgenstein says, we have reached the bedrock. There is no possible way in which one can be mistaken about certainties like 'The world exists,' 'I have a body,' 'There are others such as ourselves,' 'I am here.' What is important about Moore's truisms is that they are propositions which stands fast for us even without testing. We cannot be mistaken about what stands fast for all of us. Somewhere we must begin with not doubting with 
certainty. Moore-type propositions serve as the framework by which we can speak about the objects of the world. They have constituted the scaffolding of human thought for unthinkable ages. They are the 'substratum of all my enquiry and asserting' (OC 162). This substratum is a resting place; a place of no questions and no doubts, where our spade is turned, where we rest content. Underlying the hurly-burly of our hesitations, investigations and measurements lies the rock bottom of our conviction. This is the point of ultimate trust. From here we get our start.

The common sense framework is not a theory; it is our inherited background. What Wittgenstein takes to be foundational is a picture of the world we have implicitly assimilated, taken on as our own, inherited as members of the human community from our parents and environment, from generations of human life. We have been trained from birth in ways of acting that are nonreflective to accept a picture of the world that is ruthlessly realistic: that there is an earth, persons on it, objects in our environment, and so forth (Stroll, 1994, p.158). In the course of our daily lives we absorb such matters unreflectively and unselfconsciously. We implicitly adopt the certainty that an external world exists in order to take part in the language game of talking about physical objects. That I have a body, that there exist people other than myself, that humans cannot vanish into thin air these are animal-like or instinctual certainty that is never taught, or even articulated as such. They are 'there like our life' (OC, 559). I have never learned that I have a body, nor have I paused to consider, check or, test whether I had a body. My certainty about having a body did not await propositional formulation or any kind of focused awareness at all; it goes with having a body. I am certain of having a body in that I live and act embodied: I use my hands, speak, walk and eat. Here, to be certain does not imply that one can formulate the sentences or even understand the words that compose them. A one-year-old child not yet in possession of language shows that she is endowed with such certainties by using her body, interacting with others, running away from a barking dog rather than sitting there waiting to vanish, and so on. (MoyalSharrock, 2004, p. 104) Propositions which lie at the foundations are mostly gulped down without mention and in the course of learning many other things. Wittgenstein says in entry 143: 
I am told, for example, that someone climbed this mountain many years ago. Do I always enquire into the reliability of the teller of this story, and whether the mountain did exist years ago? A child learns there are reliable and unreliable informants much later than it learns facts which are told it. It doesn't learn at all that that mountain has existed for a long time: that is, the question whether it is so doesn't arise at all. It swallows this consequence down, so to speak, together with what it learns.

Wittgenstein's claim is that our common sense system of beliefs our inherited background - is not revisable or modifiable. Consider the following passage:

Think of chemical investigations. Lavoisier makes experiments with substances in his laboratory and now he concludes that this and that takes place when there is burning. He does not say that it might happen otherwise, another time. He has got hold of a definite world-picture-not of course one that he invented: he learned it as a child. I say world-picture and not hypothesis, because it is the matter-ofcourse foundation for his research and as such also goes unmentioned.

(OC, 167)

What Wittgenstein wants to establish here is that the world-picture that Lavoisier has got hold of supports his chemical investigations rather than getting overturned by their findings. His entire enquiry is based on certainties which he has not tested and would not think of testing: he has eyes which do not normally deceive him, he lives in a world inhabited by scientists and nonscientists, he will in some not-too-distant future need to eat and to sleep, etc. Investigative activities of science rest upon the foundations upon which are exempt from doubt: proof, justification, and therefore revision. However much Einstein's findings modified Newton's laws of motions, neither of these thinkers denied the existence of earth.

The sceptic holds that the commonsense framework is revisable in principle, and that such revisability implies the non-existence of 
certainty. Wittgenstein's position, as just discussed above, is that such propositions as "The earth has existed for many years past" and "I am a human being" are not revisable in the light of future experience. If these foundational propositions were imagined to be false, the changes it would involve in our conceptual system would be incomprehensible to us. It would be like the case if it was somehow discovered, say, by persons of another planet, that the earth came into existence two years ago, and that human beings were suffering from some pervasive distortion of the nature of time due to which they were deluded into thinking that such investigative activities as history and anthropology are really about distant past events. Such a hypothesis is logically consistent. It does not involve a logical contradiction of the kind "Some bachelors are married" (Stroll, 1994, p. 153). But such a hypothesis would make us abandon our entire explanatory system. As Wittgenstein says, any such revision would amount to the annihilation of all yardsticks (OC, 492). Our whole belief system will be plunged into chaos. It is not like the modification of Newtonian mechanics that the Einsteinian revolution effected. The existence of the earth and the communities which nurture us are not like pieces of apparatus that can be discarded or repaired if they do not work correctly. The notion of working correctly has no application to these cases. We cannot revise, alter, or question the existence of the earth. Earth and the communities that live on it stand absolutely fast. Since there is something that stands fast and is not revisable, the sceptic is mistaken in that respect as well.

When someone makes a mistake, this can be fitted into what he already knows aright. We may err in adding a long string of numbers, and this error fits into the normal pattern of human activity. We have followed the normal counting procedure, and in following it, we have run astray at some point. It is a mistake, and this misjudgement has been made in conformity with mankind. Occurrence of the mistake here presupposes that the individual making that mistake knows how to get that sort of thing right (Soles, 1982, p. 560). But we cannot be mistaken, in this sense, of the hinge propositions, of which we are objectively certain. Someone who believes that he is sitting in his room when he is not or seriously poses doubt of the existence of the world he has inherited is not making a mistake; rather he is suffering from a mental 46 
disturbance, a conceptual aberration. He will not be recognized by others to be in a position to get it right. He is knocking from under our feet the ground on which we stand in making judgments at all. Hinges are our bounds of sense. They condition our making sense. The hinge "There exist people other than myself" is a condition necessary for the use and understanding of the sense of such descriptive or informative statements as 'The world's population doubled between 1950 and 1990' (Moyal-Sharrock, 2004, p. 105). 'I am alive' is a bound of sense that ineffably underpins our thinking and acting in the world. A transgression of such bounds of sense, thinking or acting in the certainty that we might be dead or someone who died is now living, is a manifestation of madness. Our life, our deeds, show that we do not, cannot doubt some things if we are to make sense. Rejection of these bounds of sense is logically impossible, since without them we, human beings, drift into nonsense. In Wittgenstein's diagnosis then, philosophical scepticism is not merely false, but aberrant. Rebutting scepticism in this way is Wittgenstein's greatest achievement in the field of epistemology, a course that had not been followed by any previous philosopher. It is for this reason that it is being claimed in many circles that On Certainty is the most important contribution to epistemology since Kant's First Critique.

As On Certainty progresses, there grows the deepening insight that certainty itself must be understood in non-propositional ways. Objective certainty is a sureness, a trust that is not prefaced by a precursory thought or hesitation. It is not a justified or pondered assurance we come to from reasoning, observation or research. Basic certainties are not indubitable or self-justified propositions, but animal certainties. It is a non-raciocinated and unconscious trust that we share with neonates and animals. It is animal not in the sense of being brute impression, but in being unreflective. Their being non-reflective or animal invites us to think of these certainties in non-propositional terms. That physical objects exist needs no more justification than does the squirrel's instinctive gathering of nuts for the winter. The reason we put these animal certainties into words is at best heuristic. That is, we do it for philosophical analysis, the kind of thing that Moore and Wittgenstein were 
doing, or for linguistic instruction, such as a parent does who teaches his child: 'This is (what we call) a hand'. The only mode of the occurrence of objective certainty is that of showing, not of saying. It shows itself in the decisions and actions of human behaviour, in the 'give-and-take of human existence' (Gill, 1974, p. 284). Our hinge certainty that 'there are physical objects' shows itself in our reaching out to pick a flower. We show our certainty about 'This is a hand' in the way we act with and speak about this hand, for example, in our drawing a land-scape, or in our saying: 'I have cut my hand.' The hinge certainty verbalized as: 'I have a body' is a disposition which manifests itself in my acting in the certainty of having a body, for example, in my eating, running and resisting myself from taking an attempt to penetrate the walls in the spirit of a disembodied ghost. The occurrence of certainty resembles an instinctive reaction or automatic behaviour. Hinge certainty takes the form of spontaneous acting in the certainty of an innumerable number of things. It exhibits itself in the ongoing smoothness of our normal, basic operating in the world. This certainty is akin to a direct taking hold or thought-less grasp. This trust is not experienced as a trust, but rather shows itself in the absence of mistrust, in our directly 'taking hold' of something without any doubts, as when in ordinary circumstance we take hold of a towel without any preliminary hesitation and making sure that 'the towel is there'.

On Wittgenstein's view, then, the world is not primitively embraceable in thought. We take hold of it non-intellectually. In hinge perception, no epistemic route is followed, and therefore no epistemic fault can occur. There is no epistemic gap in these cases that can be infiltrated by hesitation, doubt, verification. Since in hinge perception, one is objectively, not empirically, certain of what it is one perceives, there is no possibility of a mistake. There is a natural continuity here, and therefore no actual gap between propositions which relate to our sense-impressions and propositions which relate to physical objects to be bridged and subsequently explained by philosophers. At the origin of our knowledge, there are no such preliminaries as proposition, judgment and inference, but spontaneity, automatism, rule, reflex and instinct. Here, our passage is not from the proposition to the deed. Rather, from a natural, non reflective grasp we enter the 48 
realm of sophistication, reflection and hesitating pondering. From doing to thinking. Going in this direction will not make us encounter any inexplicable gap between our thinking and our acting. No epistemic intermediaries, no protocol or observation statements intervenes between our perceiving the world and our grasping it. (Moyal-Sharrock, 2004, p.10). Sceptics overlook the spontaneity of our beginnings.

\section{References}

Gill, Jeffrey H. "Saying and Showing: Radical Themes in Wittgenstein's On Certainty" Religious Studies 10 (1974).

Martin, Dean. "On Certainty" and Religious Belief" Religious Studies vol. 20 (1984).

Moyal-Sharrock, Daniel. Understanding Wittgenstein's on Certainty. London: Palgrave Macmillan, 2004.

Pritchard, Duncan. “Wittgenstein's On Certainty and Contemporary Anti-scepticism", in Readings of Wittgenstein's On Certainty, ed. by D. Moyal-Sharrock \&W. H. Brenner. London: Palgrave Macmillan, 2005.

Pritchard, Duncan. "Wittgenstein On Scepticism" in: Oxford Handbook to Wittgenstein, ed. by Oskari Kuusela \& Marie. McGinn, Oxford: Oxford University Press, 2005.

Soles, Deborah. "Some Ways of Going Wrong: On Mistakes in On Certainty" Philosophy and Phenomenological Research vol. 42, 1982.

Stroll, Avrum. Moore and Wittgenstein on Certainty. Oxford: Oxford University Press, 1994.

Wittgenstein, Ludwig. (1949-1951/1969). On Certainty, ed. by G. E. M. Anscombe \& G. H. Von Wright, tr. by D. Paul \& G. E. M. Anscombe, Basil Blackwell, Oxford. 